\title{
STUDY OF CONDYLOID PROCESS OF THE MANDIBLE CORRELATING WITH THE AGE AND GENDER
}

\author{
Sheeja balakrishnan.
}

Assistant Professor, Govt M edical College, Palakkad, Yakkara, Kerala, India.

\section{ABSTRACT}

Introduction: $M$ andible is the largest and strongest bone of the face, muscles of mastication are attached to the mandible, it is the only movable bone of the skull in humans. Mandible consist of two processes the coronoid and condyloid process. The condyloid processes articulates with the Mandibular fossa of the temporal bone to form temporomandibular joint.

Aim of the study : To observe the variation in the Condyloid process in relation to shape side, age and sex.

Materials and M ethods: 150 dry mandible taken from various M edical colleges of palakkad. After screening the exclusive criteria detailed study of the condyloid process of the mandible is done. Divided into males and females based on the criteria. The length, width and longitudinal Axis is measured and the changes are correlated with age and sex of the mandible

Results and discussion: The size of the condyloid process was measured, variation in the length was not found between males and females. The condyloid process of both side found to almost similar length in young. The angle of mandible is measured with the help of divider and protractor. The angle of mandible changes with age, sex and dental status of the individual. In the present study the Axis of Inclination of condyloid process was measured with the help of protractor and divider. This is found to be less than or equal to the angle of the mandible in young. The angle of mandible is equal to the axis of inclination in the adult mandible. The Axis of inclination is greater than the angle of the mandible in old age. The above data provided by the present study will be help full for both dental and maxillofacial reconstruction.

Conclusion: A study on the condyloid process of the mandible shows the length of the condyloid process shows variation in the length. A normal variation of the condyloid process morphology occurs with age, force of occlusion and malocclusion between right and left side. It was found the right condyloid process is shorter than the left in both males and females. This is compared with the Angle of the mandible. It was found the Angle of mandible is greateror equal than the Axis of inclination in young mandible. The axis of inclination is equal to the angle of mandible in adult mandible and is greaterthan angle of mandible in old.

KEY WORD: Angle of mandible, condyloid process, Axis of inclination.

Address for Correspondence: Dr. Sheeja balakrishnan, Assistant Professor, Govt Medical College, Palakkad, Yakkara, Kerala, India. E-M ail: sheejabkrishna@gmail.com

\begin{tabular}{|c|c|c|}
\hline \multicolumn{3}{|c|}{ Access this Article online } \\
\hline \multirow{3}{*}{$\begin{array}{l}\text { Quick Response code } \\
\text { Dol: } 10 \text { 16965/iiar } 2017.387\end{array}$} & \multicolumn{2}{|c|}{$\begin{array}{c}\text { Web site: International Journal of Anatomy and Research } \\
\text { ISSN 2321-4287 } \\
\text { www.ijmhr.org/ijar.htm }\end{array}$} \\
\hline & $\begin{array}{l}\text { Received: } 02 \text { Aug } 2017 \\
\text { Peer Review: } 02 \text { Aug } 2017\end{array}$ & $\begin{array}{l}\text { Accepted: } 05 \text { Sep } 2017 \\
\text { Published (0): } 01 \text { Oct } 2017\end{array}$ \\
\hline & Revised: None & Published (P): 01 Oct 2017 \\
\hline
\end{tabular}

\section{INTRODUCTION}

The mandible is the largest and strongest bone of the face. The mandible come from the Latin word "jaw bone" [1]. M andible is the only movable bone of the skull, except ear ossicles [2].
The M andible consist of a body and two ramus one on left and other on right side The ramus meets with the Body at the Angle of the mandible. The ramus consists of two process coronoid and condyloid process or condyle. The 
condyloid process articulates with Mandibular fossa of the temporal bone to form temperomandibular joint The condyloid process have a round head which articulates with the temporal bone. A lower constricted part below the head is called the neck. Head and neck fracture is common in facial traumas [3]. Neck facture is more common which make in ability to protrude the mandible as lateral pretygoid is attached to it [4]. Children and Adolescent have much greater remodelling potential than adult [5]. Present study was conducted on 150 dry human mandible from the various medical colleges of Palakkkad to observe the variation in the condyloid process in relation to side, age and sex.

Aim of the Study: To observe the variation in the condyloid process in relation to shape side, age and sex.

\section{MATERIALS AND METHODS}

The present study is done on 150 dry human mandibles from medical colleges of Palakkad. The sex is identified based on the following criteria.

\section{Criteria are as follows}

\begin{tabular}{|l|c|c|}
\hline \multicolumn{1}{|c|}{ Criteria } & Males & Females \\
\hline Angle & Everted & Less Everted \\
\hline M uscular Impression & more & less \\
\hline Chin & square & round \\
\hline size & large & small \\
\hline
\end{tabular}

Bones are categorised in three $\mathbf{A}, \mathbf{B}$ and $\mathbf{C}$.

Category A includes young mandible Third molar not erupted. The mental foramen is towards the upper border of the body

Category B includes adult M andible, Third molar is erupted. The metal foramen lies between the upper and lower border of the mandible

Category $\mathbf{C}$ includes old $\mathrm{M}$ andible, The alveolar arches are resorbed. The mental foramen is towards the upper border.

Detailed study of the condyloid process is done. Length and width of the neck is measured with the divider and scale. Width of the head is measured with the scale. Longitudinal inclination and angle of the mandible is measured with the protractor, scale and divider. The following observation are correlated with side, age and sex.
Exclusive criteria: Broken Asymmetrical and deformed bones are excluded from the study

\section{OBSERVATIONS}

Out of 150 mandible taken for the study 96 was male and 54 was of females. The length of the condyloid process was taken from a tangential line drawn through the deepest part of the M andibular notch and was measured with divider and scale. The length of right and left condyloid process was taken separately. The observation of the right side is compared with the left

Fig. 1: M easurement of length of the condyloid process of Mandible.

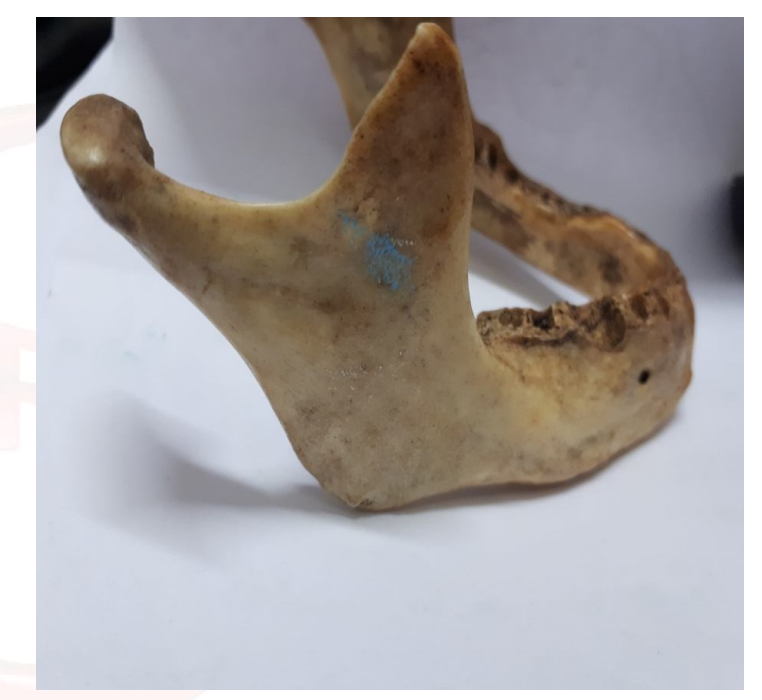

\section{LENGHT OF THE CONDYLOID PROCESS}

Table 2: Measurements of the length of condyloid process.

\begin{tabular}{|l|l|}
\hline Average length in females & $1.7625 \mathrm{~cm}$ \\
\hline Average length in males & $1.6732 \mathrm{~cm}$ \\
\hline Average length in young & $1.5562 \mathrm{~cm}$ \\
\hline Average length in adult & $1.7182 \mathrm{~cm}$ \\
\hline Average length in old & $1.8522 \mathrm{~cm}$ \\
\hline
\end{tabular}

Graph 1: Variation in length related to side Graph.

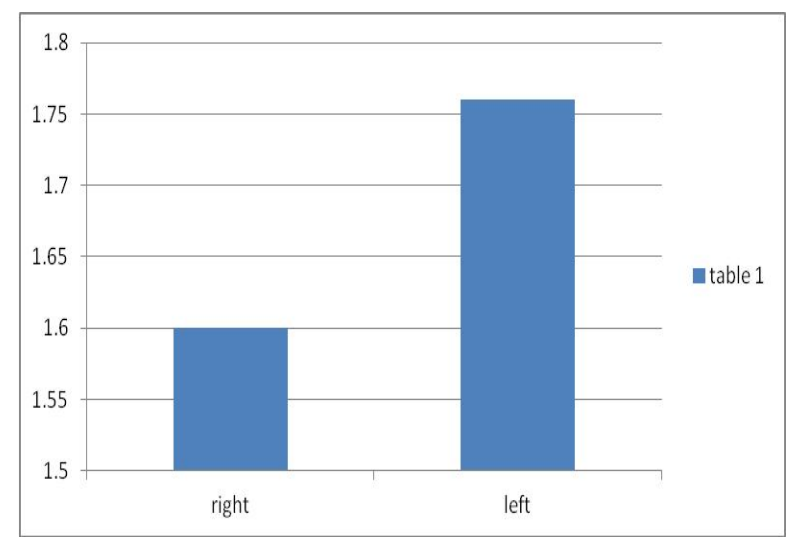


Graph 2: Variation in length of condyloid process related to Age.

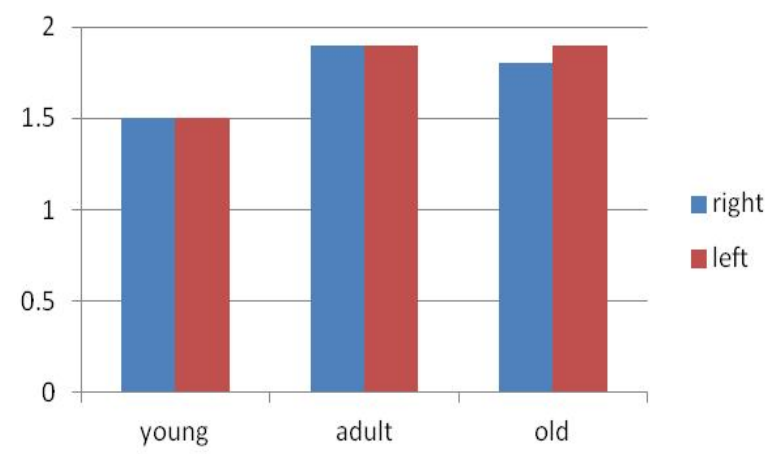

Angle of the mandible is measured with protractor and divider. The angle of right side of the mandible and left side is taken separately and compared with age

Graph 3: Variation in the angle of the mandible with age.

Y-Values

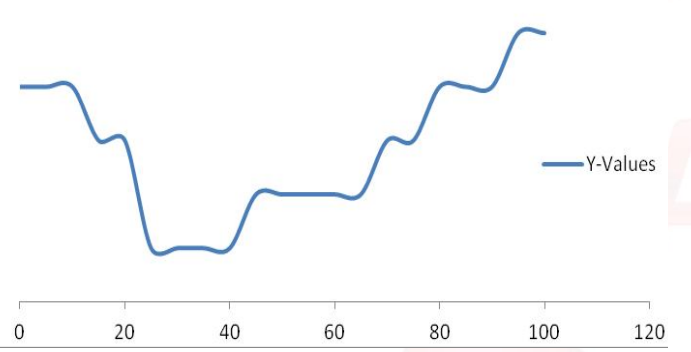

The angle of inclination taken with the help of the protractor and the divider. Angle is measured in young mandible it is found to be $122 \pm 2$ which is almost similar or less than the angle of mandible ( $P$ >.05). Angle of inclination of condyloid process was taken in adult mandible. It is found to be $119 \pm 2$. It is similar to that of the angle of the mandible $(P<001)$. The Angle of inclination of condyloid process of old mandible is taken it is found to be $120 \pm 2$ which is found to be greater than the angle of the adult mandible which value is $115 \pm 3, p$ valve is found to be $>.05$

Graph 4: Variation in the angle of inclination of condyloid process with age.

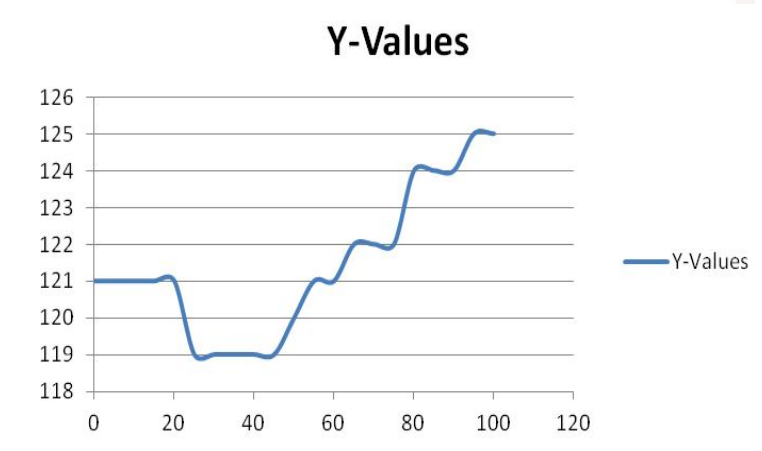

Int J Anat Res 2017, 5(4.1):4519-22. ISSN 2321-4287
Graph 5: Variation in the angle of mandible with angle of Inclination.

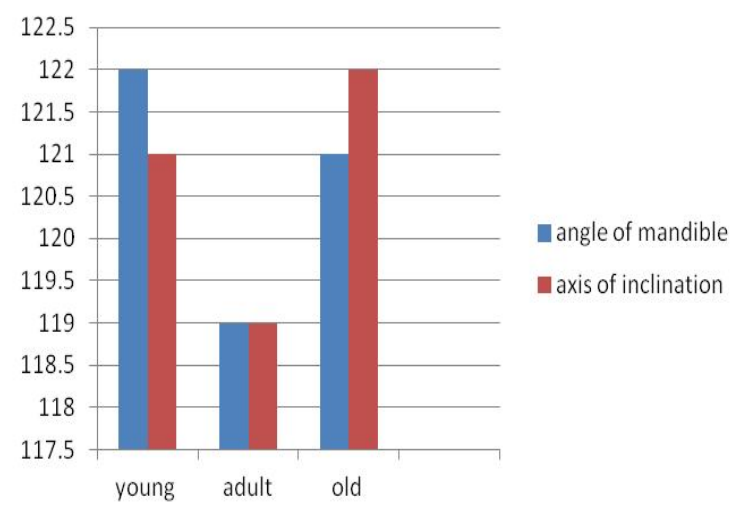

\section{DISCUSSION}

The mandible is the strongest and lowest bone in the face. The ramus of the mandible have two process coronoid and condyloid process. Each condyloid process articulates with the mandibular fossa of the temporal bone at temperomandibular joint [6].

The mandibular Condyle varies considerably both in size and shape [7]. The anteroposterior diamension of the condyle is approximately 1 $\mathrm{cm}$. The medial aspect of the condyle is wider than lateral. The long axis of the condyle lies in a coronal plane with ramus of the mandible [8].

Out of the 150 mandible taken 54 were female and 96 were males. The length of the condyle was taken both on right and left side separately by drawing a tangential line through the massetric notch of the mandible with the help of divider and scale. Asymmetries between the right and left condyle were common. A normal variation of the condyle morphology occurs with age, force of occlusion and malocclusion between right and left side [9]. It was found the right condylar process is shorter than the left in both males and females. The length of the condylar process were significantly greater on non deviated side of the person than deviated side which leads into mandibular asymmetry [10].

The size of the condyloid process was measured and found to be approximately $1.75 \mathrm{~cm}$. No much variation in the length was found between males and females. The condyloid process of both side were found to almost similar length in young. The difference in the length becomes noticeable in adult mandible. The left sided condyloid is found to be longer than the right condyle in old 
mandible with edentouds type of mandible. A part from the genetic factors, the left condyle is found to be longer the right condyle. This lateralization effect largely depends on the mastigatory behaviour of the individual [11]. The length of the articular surface of the mandible is measured it is found approximately $1 \mathrm{~cm}$ [12]. No much noticeable variation in the size of the head of the mandible is seen.

The angle of mandible is measured with the help of divider and protractor the angle of mandible chages with age, sex and dental status of the individual [13]. It was found that the angle of mandible is greater in young reduces in adult which is usually less than 120 degree [14]. Angle of the mandible again increases with age [15].

In the present study the angle of inclination was measured with the help of protractor and divider. The angle of inclination is found to be less than or equal to the angle of the mandible in young .The angle of mandible is equal to the axis of inclination in the adult mandible. The angle of inclination is greater than the angle of the mandible is old age. The above data provided by the present study will be help full for both dental and maxillofacial reconstruction. The gonial depth can be implicated as a forensic tool for gender determination but not suitable for age determination [16].

\section{CONCLUSION}

A study on the condyloid process of the mandible shows the length of the condyloid process shows variation in the length. A normal variation of the condyle morphology occurs with age, force of occlusion and malocclusion between right and left side. It was found the right condylar process is shorter than the left in both males and females. The length of the condylar process were significantly greater on non deviated side of the person than deviated side which leads into mandibular asymmetry. The length of the condyloid process is found to be approximately $1.7 \mathrm{~cm}$. The length of the articular surface of the mandible is found to be $1.7 \mathrm{~cm}$ which is almost similar to the length of the condyloid process. The axis of inclination is compared with the angle of the mandible. It was found the angle of mandible is greater than the axis of inclination in young mandible. The axis of inclination is equal to the angle of mandible in adult mandible and is greater than angle in old or edendous mandible.

\section{Conflicts of Interests: None \\ REFERENCES}

[1]. Nasif Ahammad faruqi ,M andible. A clinical orientation human osteology. 2002;273-274.

[2]. S poddar, Ajay Bhagath, M andible Hand book of osteology. 2013;97-99.

[3]. LarsLindahl, Lars Hollender. Condylar fractures of the mandible:II. A radiographic study of remo deling processes in Temporomandibular joint, International journel of oral surgery 1977;6(3):153-165.

[4]. M urray GM , Phanachet I, Uchida S.The human lateral pterygoid muscle: A review of some experimental aspects and possible clinical relevance. Australian dental journel 2004;49(1):2-8.

[5]. M ichael F. Zide DDSOpens. John N. Kent DDS. Indications for open reduction of mandibular condyle fractures. 1983;4(2):89-98.

[6]. Gray's Anatomy Fortienth Edition,Susan Standring ;469-470,2010

[7]. Jose valladares Neto,Carles Estrela et Mandibular diamension changes in subjects from 3-20 years using cone beam C.T.a preliminary study. Dental press of orthod. 2010;15(5).

[8]. Gray's Anatomy Fortienth Edition,Susan Standring 2010;469-470.

[9]. Tazuko. K. Goto and greeling E.J Langenbach, Condylar process contribute to mandibular Asymmetry (In vivo 3D M RI study),Clinical Anatomy. 2013;27(4):17.

[10]. Ram Ballabh Upadhyay, Juhi Upadhyay, Pankaj Agrawal and Nirmala N Rao2. Analysis of gonial angle in relation to age, gender, and dentition status by radiological and anthropometric methods. Journel of Forensic dental sciences, 2012;4(1):2933.

[11]. Revant H. Chole, Ranjitkumar N. Patil, Swati Balsaraf Chole, Shailesh Gondivkar, Amol R. Gadbail, and Monal B. Yuwanati, Association of Mandible Anatomy with Age, Gender, and Dental Status: A Radiographic Study ,ISRN Radiology,2013

[12]. Jodi Leversha, Glen M cKeough, Adriana Myrteza, Hannah Skjellrup-Wakefiled, Jordan Welsh. Age and gender correlation of gonial angle, ramus height and bigonial width in dentate subjects in a dental school in Far North Queensland, journal of Experimental and clinical Dentistr 2016;8(1):49-54.

[13]. Wataru Kawashima, M amoru Uemura, Isumi Toda, Hiroichi Orihara, Nobutaka Okusa and Akimichi Takemura. Age estimation from Mandibular angle and oral findings on three-dimensional computed tomography , Journal of Osaka dental University, 2016;50(1):7-11. 